\title{
Using Research Techniques to Teach Management of IT Concepts to Postgraduate Business Students
}

\author{
Stephen Burgess and G. Michael McGrath \\ Victoria University, Melbourne, Victoria, Australia
}

Stephen.Burgess@vu.edu.au; Michael.McGrath@vu.edu.au

\begin{abstract}
This paper examines the delivery of concepts related to the role of the information technology (IT) manager of an organisation and management of the organisation's information technology department to Masters level students in a business faculty of an Australian University. Initially, the development of a course designed to teach concepts related to the management of information technology in the Masters of Business (Information Systems) program (and similar programs) offered by Victoria University in Australia is outlined. The lecturers adopt a 'constructivist' approach to delivering the course, encouraging students to relate the course material to their own view of the world. Two learning activities in particular are examined to demonstrate how research techniques can be used to teach such management concepts. A unique feature of the paper is that it reports on recent delivery of the course in a new environment where the university encourages learning in the workplace and community and the adoption of new strategies to achieve student success.
\end{abstract}

Keywords: management of information technology; concepts; postgraduate; business students

\section{Introduction}

This paper examines the teaching of concepts related to the role of the information technology (IT) manager of an organisation and the management of an information technology department, and, particularly, a course in the Master of Business (Information Systems) program offered by Victoria University in Melbourne, Australia - the core course BCO6653 Management of Information Technology. (Note that, while we refer to students undertaking this course as being at 'postgraduate' level, in the USA and some other places, they would be classified as 'graduate' students.) A quick review of the development of the assessment of the course is provided to demonstrate how a 'practical' understanding of concepts related to the management of information technology in an organisation can be

Material published as part of this publication, either on-line or in print, is copyrighted by the Informing Science Institute. Permission to make digital or paper copy of part or all of these works for personal or classroom use is granted without fee provided that the copies are not made or distributed for profit or commercial advantage AND that copies 1) bear this notice in full and 2) give the full citation on the first page. It is permissible to abstract these works so long as credit is given. To copy in all other cases or to republish or to post on a server or to redistribute to lists requires specific permission and payment of a fee. Contact Publisher@InformingScience.org to request redistribution permission. developed through the use of research techniques. The course is then reassessed according to two university imposed requirements - learning in the workplace and community and introduction of new strategies to achieve student success. 


\section{Background}

It is important that any delivery of courses involving information technology that result in students either using or associating with the use of IT should have practical implications. Hosseini (1993) identified some challenges to teaching Management Information Systems (MIS) concepts. One challenge is that the abstract nature of the concepts surrounding the development and management of IT systems makes these concepts difficult to teach in the classroom. Much of this is due to the observation that students do not have work experience involving the management and use of IT. This means that there is a lack of any practical frame of reference for students, and this makes it difficult for them to appreciate IT management issues. Thus the major issue addressed in this paper is the development of teaching and learning strategies (and methods) that compensate for this lack of student's practical experience and, at the same time, expose them to the challenges faced by real IT managers, confronted by real problems in real settings.

Of course, students are now more IT savvy than they were in 1993 - although it could be argued that they still often lack managerial experience. One approach that could be used to represent practical concepts to students is that of 'constructivism.' Biggs (1999) advocated the concept of constructivism in teaching, where students' learning is based on the degree to which the content of a course is made meaningful to them in relation to their own 'view of the world.' Thus, in order for students to learn, they must be able to personally construct meaning from the material that is delivered. This is evident if students feel a 'need-to-know':

When students feel this need-to-know, they try to focus an underlying meaning: on main ideas, themes, principles or successful applications...students needing to know will naturally try to learn the details as well as making sure they understand. When using the deep approach in handling a task, students have positive feelings: interest, a sense of importance, challenge, even of exhilaration. (Biggs, 1999, p. 16)

One way this can occur is through the structuring of learning activities that pose a question or problem to a student, and then motivate the student to look for information that will find solutions, to assess the relevance of the information, and to communicate what they have found. It could be argued that applying this technique can be an effective strategy in facilitating a student's learning of 'management of IT' issues.

\section{Practical Applications of Information Systems Research}

One approach that could be used to encourage student learning in such a manner is to encourage them to find solutions to their problems using a research approach. In particular, Williamson, Burstein, and McKemmish (2002, p. 12) suggest a number of reasons as to why research should play a part in professional practice. Included in these reasons are the following:

- To assist in understanding problems and issues in the workplace

- To add to knowledge in the field and/or provide solutions to problems

- To provide a body of research findings and theory to inform practitioners.

Research that is conducted specifically in the information systems field is often associated with very practical applications.

Information systems researchers draw problems for investigation from practice and the results of their studies usually generate theories, which need to be applied and tested by practitioners in the context of the real world information systems. Information systems researchers are very conscious about the usefulness of their research results to 
industry as well as the rigour of their approaches and their contribution to the core knowledge of the information systems field. (Williamson et al., 2000, pp. 17-18)

Towards the end of the last century, Benbasat and Zmud (1999) suggested that the relevance of information systems research was not assured with the selection of a 'relevant' topic. The results of the research must be implementable before practitioners will take an interest in it.

In discussing this type of research, Urwin and Burgess (2007) discuss the importance of matching the research strategy with the type of research to be undertaken and the need to choose appropriate research strategies:

- to satisfy the objectives of the researcher

- to overcome the ignorance of the researcher (of alternative research perspectives, methods and analyses)

- to satisfy the objectives of other interested parties (such as practitioners)

- that are achievable within the resource constraints of the research.

In the following case study the intention is to show how the concepts of constructivism in teaching, combined with access to practical IS research techniques, can provide students of a Masters program in information systems with a view of what is required in the effective management of an IT department. In the first instance a summary of how the 'research' approach is applied to the learning activities of the course.

It must be emphasised that no claim is made that the approach detailed here is the only way in which this 'lack of experience' problem might be addressed or, indeed, that it is intrinsically superior to alternative strategies. Other methods that might be adopted include problem-based research (Ellis \& Levy, 2008), case studies (Angel, 2001) and, more recently, role-playing in virtual worlds (perhaps combined with relevant case studies) (Kohler, Fueller, Stieger, \& Matzler, 2010). These, however, are beyond the scope of this paper.

\section{A Case Study at Victoria University}

This section is summarised from Burgess and Reyes (2004).Victoria University is located in Melbourne, Australia and has three 'higher education' faculties - the Faculty of Business and Law being the one relevant to this paper. In 2008 a faculty restructure occurred and the School of Management and Information Systems was formed from the previously separate School of Management, School of Information Systems, and the Faculty's Graduate School of Business (which offers its MBA and DBA programs).

The School of Information Systems began offering a Master of Business in Business Computing (now Information Systems) in the mid 1990s. This degree became quite popular, particularly with overseas students travelling to Melbourne to study. However, due to the worldwide drop in interest in IT courses in the 2000s, enrolments in the program plummeted. However, during this time, enrolments were quite strong in the School's Master of Business (Enterprise Resource Planning) program and subsequently in a special offering that merged the two programs into a 'double' degree. The Masters degree format is a total of 12 courses, usually taken over three semesters full time. With cross credits, the double degree program is offered over four semesters full time.

A core course in these programs, and one of the first courses that students study, is BCO6653 Management of Information Technology. The purpose of this course is to introduce students to the issues faced by the manager of an IT department. Specifically, the course aims to ensure that students will:

- Be familiar with current research and developments in IT management, 
- Be familiar with important management issues in managing IT,

- Understand the information management approach, its nature and importance,

- Be able to apply relevant methods and techniques to better manage information resources,

- Have applied a relevant research method (or part of a method) to an organisation or part of an organisation and prepared a report,

- Plan and prepare a substantial research paper on a designated topic,

- Have critically reviewed research papers, presented evaluations and led group discussions on the evaluations.

In order to do this, the course is based around a number of major issues that are examined in each of the two major learning activities. The number of issues covered varies slightly from semester to semester. As of semester two, 2009 the issues were:

- Information systems planning

- Organisational Impacts of IT Use

- IT Organisation structures

- Use of IT for Competitive Advantage

- Analysis of IT Investment: Value and Risk

- Knowledge Management

- Managing the Human Resource

- IT Governance

Many of these topics are covered in other courses in the program. However, an important component of this course is that it concentrates upon each of the topics in relation to how they are managed within an actual IT department in an organisation and how IT managers manage resources related to each of the topics within the department. Students are constantly reminded of this as they prepare their assessment tasks for the course.

The course is divided into two major sections. The first half of the course (six weeks) is divided into a series of 'mini' presentations related to each of the topics, delivered by the course lecturers and, sometimes, guest speakers. This is designed to introduce the topics to the students, allowing them to see how many of them are interrelated and providing them with some basis by which they can select which of the topics they would prefer to examine in greater depth.

The second half of the course is divided into two sections and is where the students take over the presentation of seminars. This assessment occurs via two major learning activities.

\section{Learning Activity: Literature Analysis}

The semester (which runs for 12 weeks) commences with the lecturers outlining the objectives of the course. The first few weeks of the course are run in traditional lecture/ tutorial format. In weeks $2-5$, lectures briefly cover two or three of the major topics - with the aim of providing an overview of each topic to students - a 'shell' which the students can then 'fill' with the learning activities.

During these early weeks, tutorials involve providing students with the skills to carry out a literature analysis to search for peer reviewed articles related to their topic. Thus, they are taken through the basics of searching for articles, learn to understand the difference between sourcing articles from different sources (such as peer-reviewed articles versus online newspaper or magazine articles), and are trained to assemble a simple literature review. 
One might ask, "Why a literature review?" Essentially, it was considered important that students understood that they had access to information that came from sources that could generally be relied upon. Blank (1984) identified some of the benefits of the use of literature reviews as:

- Providing access to inaccessible subjects: access to research that has been carried out in areas that the student does not have access to

- Longitudinal analysis: there can be access to historical data for studies carried out over a lengthy period of time

- Relatively low cost: it is cheaper for students to conduct a literature review than to carry out the same research themselves (it is also faster)

- High quality: this is especially the case if literature used is peer-reviewed, in respectable journals and/or written by experts in the field

It is necessary to spend some weeks training students to prepare a literature review as they need to be aware that some studies they source may be incomplete and difficult to find (although the latter is less of a problem these days with electronic publishing). The main challenge faced by students is that they need to be aware that peer-reviewed articles are not in a standard format (Blank 1984) and that they may employ differing terminology, often due to studies being carried out in different locations or at different times. Students also need to be provided with the skills to be able to assemble the literature into a logical argument.

The first learning activity allows students to select one of the major topics and investigate it in some depth - with the purpose of presenting a seminar related to the topic. The seminars for this learning activity operate over three weeks. In each week, two or three of the topics are covered. Although they deliver one topic 'in depth' students are also assessed on their contribution to the discussion on each of the other topics - thus they are exposed to each of the topics at some depth by delivering seminars, listening to seminar presentations, or participating in discussions. The seminar presentations are based upon a paper that students prepare for the topic. The paper is based upon 'theory' (the literature review section) and 'practice'.

As already mentioned, for 'theory', the students have to search online databases (such as Business Source Premier) for materials to prepare a 'mini' literature analysis. At this stage they have had the value of selecting 'peer reviewed' journals over just selecting general web site information found using a search engine explained to them.

However, the literature review is also contrasted with a 'practical' component, where the students have to relate what they have discovered in their literature analysis with a 'real' application. In recent semesters these have included the use of case studies in each of the major topic areas or reference to materials gathered from 'online' magazines for IT managers (such as www.CIO.com). These cases and online sources are drawn from around the world.

In this way the students are introduced to the notion of gathering the best research in the area from peer-reviewed publications and comparing it to 'actual' practice.

\section{Learning Activity: 'Real' Practice}

In the early years of this course, the second learning activity was also an in-depth literature analysis and presentation based upon a selected topic. However, students indicated that they were feeling less fulfilled by this assignment after having had a taste of matching theory and practice in the first assignment. It was therefore decided to introduce a 'practical' aspect of this assignment as well - in the form of interviews with real IT managers. Thus, another research technique - the collection of data via interviews - was employed. 
Group work was encouraged, but not forced, upon students throughout the course. Typically, groups of two to four students and the occasional sole student would prepare the assessment tasks. Varying the size of the paper and the length of the presentation for different sized groups moderated this. Initially, each 'group' was expected to perform a literature analysis and develop a set of questions for four topics, despite the number of students in the group. What varied was the amount of the literature and number of questions for each topic per group. The questions would then go on to form the basis of an interview that had to be conducted with an IT Manager of two businesses (which the students were required to find themselves). The only requirement for the business was that it had to have an IT department of at least five employees. The students would then be expected to write up the interviews and make a comparison between the literature and the interviews.

Although the overall concept worked quite well (students were overwhelming in their appreciation of the assignment) there were a number of problems:

- The smaller groups and 'sole' students were quite overwhelmed by the need to cover four topics, even at lesser depth than the other groups.

- The standard of questions being put together by students varied significantly. Many of them were quite inappropriate (e.g., "How often do you sack IT employees and why?").

- Many of the students complained that they did not have enough time to contact the companies and conduct the interviews.

Thus, the assignment was changed so that the number of topics to be covered related to the number of members in the group. For instance, a group of four students would have to cover four topics. This seemed to work quite well (except that some students working by themselves complained that they did not get to ask many questions at the interview stage!). An assessable 'milestone' was introduced for the assignment, forcing the students to start work on the assignment earlier, but still there were some students that left the search for businesses until too late. There was no backup strategy for them if the business they selected would not respond. Some students that could not find businesses to respond actually resorted to 'inventing' companies and responses, which was quite obvious from the standard of responses that were reported. Written assistance for the development of interview questions (and some sample questions) was provided, but still the standard of questions being developed was quite poor and they required a fair amount of editing before they were suitable to be used in interviews.

Due to the low standard of questions being prepared by students, it was decided to prepare a series of questions in advance for students to use. This did, however, mean that the research process was a little out of sequence for the students. Instead of them searching the literature and identifying gaps and subsequent questions to ask, they were provided with the questions and then required to find matching literature. In the end, this turned out better than anticipated with students having little difficulty finding relevant literature, as the questions were quite generic (for instance, one question related to the relative advantages and disadvantages of outsourcing the IT function).

Further milestones were introduced, forcing students to start work on the second learning activity as they were still involved in the first learning activity. These milestones related to identifying the companies (with potential backup companies) and topics, contacting IT managers, developing the literature analysis for their topics, and conducting the interviews - all to be completed by the week before the assessment task was due. The feedback from students to this initiative was quite positive. 
In relation to students inventing companies, asking students to supply the URLs of the business' web sites discouraged this. They were informed that URLs that included generic titles such as 'Yahoo' or 'Hotmail' in the address would not be accepted.

By this stage the problems associated with the assignments were somewhat more specific. Students were still having some difficulties finding suitable businesses but the lecturers were learning some lessons in relation to what types of business were likely to respond positively.

One very effective recent change to the learning activity was the requirement that students gain approval for the interviews from IT managers via email - and also conduct the interviews via email. This had the advantage of providing an audit trail of the students' interactions with IT managers - but also the additional advantage that students could access IT managers from businesses around the world. This provided a greater opportunity (for overseas students especially) to be able to interview IT managers from businesses in their own countries - and had the added advantage of providing an international flavour to the learning activities. For instance, in the recently completed semester (Semester Two, 2009), the IT managers that were interviewed came from companies in Australia (50\%), India (25\%), Saudi Arabia (10\%), Thailand (10\%), and Singapore (5\%).

Summarising, the lecturers attempted to develop the course so that the students were provided with access to recent (practical) research in each of the particular major topic areas; they also were able to appreciate the applicability of these concepts in IT departments. This was by having access to web sites such as 'CIO.com', conducting their own interviews with IT managers, and listening to the presentations of students that had conducted their own interviews. In this way, the students were able to use their newly acquired research skills to construct their idea of the conduct of the management of an IT department according to their own view of the world.

\section{An 'Old' Approach to a 'New' Environment}

\section{Making VU}

In 2007, Victoria University announced a new series of priorities for the university, known as 'Making VU: A New School of Thought.' These priorities consisted of five commitments that would drive the activities of the university and would underpin them. Although given until 2016 to fully implement Making VU, a number of the commitments are well advanced. The commitments are:

- Commitment 1: Industry and Community Clusters. The aim of this commitment is to focus on 11 industry and community 'clusters' with input to the University's activities from roundtables chaired by prominent industry and community leaders. The School's offerings are split between the 'Management and Marketing Services' cluster and the 'Transport and Logistics' cluster. There is no dedicated IT cluster. This commitment is not seen as a focus of this paper - although any new course initiatives will be considered at some stage by the relevant clusters.

- Commitment 2: Learning in the Workplace and Community. The aim of this commitment is to make learning in the workplace and the community a universal feature of VU courses (with at least $25 \%$ of the assessment of course offerings involving learning in the workplace and community).

- Commitment 3: Strategies for Student Success. This commitment acknowledges the diversity of the VU student population and provides a strategy action framework through which VU 
aims to foster student success and engagement. This commitment involves, amongst other things, supporting student learning rather than just teaching and providing flexible pathways and delivery options for students. Another important aspect of this commitment is for the university to respond to student diversity.

- Commitment 4: Workforce futures. This commitment is concerned with the vocational education arm of Victoria University and is thus not a focus of this paper.

- Commitment 5: Community: Initiatives for the West. This commitment is concerned with resourcing new initiatives aimed at improving life in the western region of Melbourne. Victoria University is the only Australian university located in the region and its development is seen as vital. This commitment is not a focus of this paper.

Commitments 2 and 3 will now be discussed in relation to the Management of Information Technology course, BCO6653.

\section{Learning in the Workplace and Community (LiWC)}

In an internal report prepared for Victoria University, Orrell (2007) identified the recent increase in university programs requiring a component where students learn in the workplace as opposed to in the classroom. Drivers for LiWC include (Orrell, 2007):

- A potential for gaining professional accreditation

- Students being given the chance to explore the world in relation to their discipline

- A chance for students to 'sample' their potential careers

- The chance to tackle 'real world' problems for 'real' clients

- The increased likelihood of students being 'work ready' upon graduation

- The chance to transfer knowledge and skills gained in the classroom into everyday practice

- The enhancement of university and industry partnerships.

Drawbacks associated with LiWC include negative attitudes by both students and academic staff as it can be seen to be yet another requirement placed upon them, that it requires some effort to create effective LiWC settings, and that it can be an interruption to 'real' learning (Orrell, 2007).

One technique that Victoria University uses to minimise the drawbacks associated with LiWC is to adopt a wide definition of LiWC and to link it specifically to learning activities. The wide definition of LiWC means that it does not necessarily involve some type of placement in an organisation - it can also be on campus where projects are being completed for a workplace or community enterprise, or on campus working on a VU-specific project. It is felt that utilising a range of these contexts throughout a program will provide diverse opportunities for experiential learning for students

Thus, in the case of the Management of Information Technology course, the two major learning activities can be examined to see if they contain characteristics that incorporate aspects of LiWC. To qualify, the learning activities typically have to have (amongst other characteristics) support from the workplace and a three-way agreement between workplace, university, and student. Clearly this is not the case in the first learning activity as it primarily involves a literature review. However, the second learning activity does involve a VU-specific project (investigating an issue related to the management of IT) with managers in the workplace and students. In fact, students are required to approach IT managers with a letter from the VU lecturer, and the managers are required to confirm their participation in the learning activity. Thus, the three-way agreement is established (formally) and the learning activity qualifies as LiWC. As the activity is worth $60 \%$ of the assessment, it easily qualifies for the $25 \%$ requirement for the course. 


\section{Strategies for Student Success}

One of the key aspects of this commitment, which is quite wide-ranging, is to emphasise the importance of student learning rather than just teaching. One technique used to foster this is to encourage collaborative learning through the provision of collaborative workplaces and to provide encouragement for students to operate within groups. Whilst not compulsory, most students in the Management of Information Technology course do elect to work in groups (in Semester 2, 2009, $89 \%$ of students worked in groups). This type of learning is supported as it involves students working in small groups to gain understanding, search for meaning, develop skills, solve problems, or create a product in an environment where the responsibility for learning is shared amongst members of the group. Thus, the learning becomes a student-centred approach and represents a significant shift away from the traditional teacher-centred approach. After the early weeks when the topics are introduced, student presentations, seminars, and question-answer sessions are the only form of classroom delivery for the remainder of the semester.

Note also that one of the advantages of the student-centred learning is that it allows the students to search for meanings - which is consistent with the constructivist approach of the lecturers mentioned earlier.

Another important aspect of this commitment is the requirement to embrace student diversity. VU's core student group is predominantly made up local students from Melbourne's western suburbs (a typically low-socioeconomic area with a wide ethnic profile) and overseas students. Thus, any course which relied solely on a technique of delivering 'Western' principles to 'Western' students would quickly be found out to be inappropriate. As shown earlier, the Management of Information Technology course embraces its international student cohort and utilises them to bring experiences from around the globe so that other students' views of the world can be broadened.

Finally, placing such a strong emphasis on the development of research techniques provides students with skills they will find extremely useful in other subjects they are required to take and, indeed, in their future careers (an aspect of the course also relevant to the LiWC commitment).

\section{Conclusion}

This paper has summarised the approaches taken by lecturers to deliver concepts related to the management of IT to students who have not previously had exposure to this environment. The lecturers have made a conscious effort to develop the course in such a way that the students have a way of relating the theory of the course to the actual management of IT as it occurs in 'real life', using research activities such as the literature review and interviews. It is believed that this approach allows the students to construct their own meaning according to their own views of the world of their experiences gained within the course. They are encouraged to work in groups to enhance this learning experience. Although the course was designed before the introduction of 'Making VU,' the course fits well with the key commitments of the initiative. Two of these, learning in the workplace and community and strategies for student success, were discussed in this paper.

To summarise, this paper has addressed the important (indeed, fundamental) IT teaching and learning issue that: i) ideally, IT management education should focus on practical problems and challenges in real, industry-based settings; and ii) most students lack the experience to appreciate the essence (let alone the nuances) of problems and solutions, plus connections and contingencies related to same. A potential solution to this is to expose students to the realities of the practical problems faced by IT managers through a 'learning in the workplace' approach, complemented 
by a research-based learning strategy, underpinned by constructivism. In the specific case reported on in this paper, the outcomes appear to have been very positive. External validity considerations, however, demand further research - possibly through additional case studies using a replication logic approach (Yin, 2003).

Finally, we are currently considering a number of additional means of enriching our students' learning experience and doing so in a 'fun' way that may well provide them with an even-more intense exposure to IT management within practical settings. Of particular promise here are recent developments in 'virtual worlds' (see e.g., Kohler et al., 2010). That is, rather than the current, traditional presentation of findings, it may well be possible to have individuals and groups role-play and use their avatars to present results, argue, and negotiate (around some central, integrating issue or problem) within a virtual IT management world.

\section{References}

Angel, N. F. (2001). Teaching information systems management: An interactive case approach that is portfolio oriented. Journal of Computing Sciences in Colleges, 16(2), 286-296.

Benbasat, I., \& Zmud, R. W. (1999). Empirical research in information systems: The practice of relevance. MIS Quarterly, 23(1), 3-16.

Biggs, J. (1999). Teaching for quality learning at university: What the student does. Buckingham: Society for Research in Higher Education and Open University Press.

Blank, S. (1984). Practical business research methods. Connecticut: AVI Publishing.

Burgess, S. \& Reyes, G. (2004). Teaching business students about the management of IT: Matching theory to practice. Innovations Through Information Technology: Proceedings of the 2004 Information Resources Management Association Conference, Ed. M. Khosrow-Pour, Idea Group Publishing, Hershey, PA.

Ellis, T. J., \& Levy, Y. (2008). A framework of problem-based research: A guide for novice researchers on the development of a research-worthy problem. Informing Science: the International Journal of an Emerging Transdiscipline, 11, 17-33. Retrieved from http://www.inform.nu/Articles/Vol11/ISJv11p017-033Ellis486.pdf

Hosseini, J. (1993). Application of Bloom's taxonomy and Piaget model of cognitive processes to teaching of management information systems concepts. Journal of Information Systems Education, 5(3), 1-12.

Kohler, T., Fueller, J., Stieger, D., \& Matzler, K. (2010). Avatar-based innovation: Consequences of the virtual co-creation experience. Proceedings of the 43rd Hawaii International Conference on System Sciences, Kauai, Hawaii, 5-8 January, 2010.

Orrell, J (2007). The value of learning in the workplace and community. Victoria University Internal Paper, Melbourne, Australia

Urwin, G., \& Burgess, S. (2007). Promoting research between communities of practice. International Journal of Computers, Systems and Signals, 8(2), 27-35.

Williamson, K., Burstein, F., \& McKemmish, S. (2002). The two major traditions of research. In K. Williamson, Research methods for students and professionals: Information management and systems (2nd ed.). Wagga Wagga, Australia: Centre for Information Studies, Charles Sturt University.

Yin, R. K. (2003). Case study research: Design and methods (3rd ed.). Thousand Oaks, CA, USA: Sage. 


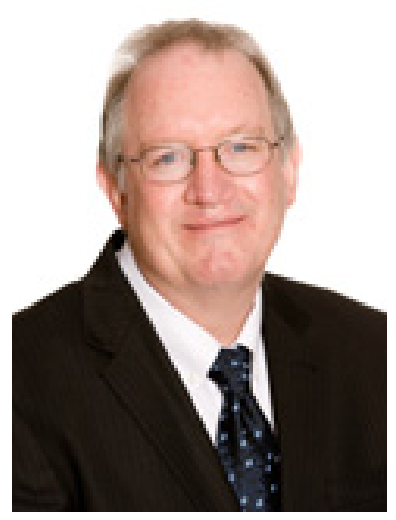

\section{Biographies}

Dr Stephen Burgess is currently Associate Professor in the School of Management and Information Systems at Victoria University, Australia, He has research and teaching interests that include the use of ICTs in small businesses (particularly in the tourism field), and B2C electronic commerce, receiving a number of competitive research grants in these areas. He has completed several studies related to website features in small businesses and how well websites function over time, including his $\mathrm{PhD}$ from Monash University, Australia (completed in 2002). He has authored/ edited three books and special editions of journals in topics related to the use of ICTs in small business and been track chair at the international conferences in related areas. More recently, Stephen has extended his research interests to include the use of websites by community based organisations. He has published in journals such as the Journal of Information Science, Information Systems Frontiers, the International Journal of Tourism Research and the Journal of Hospitality, Marketing and Management.

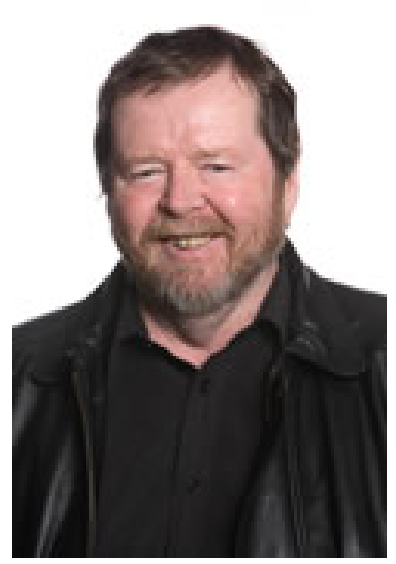

Dr. Michael McGrath is currently Professor of Information Systems at Victoria University, Melbourne, Australia. Before taking up an academic position he had over 20 years experience in the IT industry mostly at Telstra, Australia, where he worked in a variety of positions. These included an executive-level position, as Manager Information Architecture within the organisation's Corporate Strategy Directorate. His current research is focused mainly on the development of a highlevel information architecture for the Australian tourism industry and on developing various decision support systems (DSS) for use by destination managers and small-to-medium tourism enterprises (SMTEs). He has authored over 120 refereed journal and conference papers. 